\title{
Decision-making in state lotteries: Half now or all of it later?
}

\author{
FOREST BAKER, MATTHEW W. JOHNSON, and WARREN K. BICKEL \\ University of Vermont, Burlington, Vermont
}

\begin{abstract}
Many state lotteries offer players a choice between receiving roughly half of the jackpot immediately and receiving the entire jackpot over 25 annual payments. This requires players to make a decision that involves uncertainty, delay, and large amounts of real money. Archival data on lottery players' jackpot payment decisions were collected from seven state and three multistate lotteries. Players'jackpot payment preferences were assessed at the time of ticket purchase and after winning a jackpot. Preference for the annuity payment option significantly decreased as jackpot size increased, both at the time of ticket purchase and after winning. Furthermore, a significant proportion of winners who selected the annuity payment option at ticket purchase switched to the cash payment option after winning, whereas no winners switched from the cash to the annuity option after winning. These findings suggest that real-world choices involving large sums of money may be subject to diminishing marginal utility and probability and delay discounting.
\end{abstract}

A 1999 Gallup poll found that lotteries were the most popular form of gambling for Americans, with $57 \%$ of the respondents reporting that they had bought a lottery ticket in the past year. A relatively new feature of many state and multistate lotteries in the United States is that players get to choose how they receive a jackpot. That is, many lotteries offer players a choice between receiving roughly half of the jackpot immediately, the "cash" payment option, and receiving the entire jackpot in 25 (30 for some state lotteries) annual payments, the "annuity" payment option. For example, if a person won a $\$ 25$ million jackpot and she chose the annuity payment option, she would receive close to $\$ 1$ million immediately and 24 more annual payments, for a total of $\$ 25$ million. ${ }^{1}$ If she chose the cash payment option, she would receive close to $\$ 12.5$ million immediately (before taxes).

Lottery payment decisions are relevant to research on judgment and decision-making because they involve uncertainty, delay, and large amounts of real money. Research on the effects of uncertainty and delay on decision-making is largely based on studies that have used hypothetical rewards. The few studies that have actually presented participants with choices pertaining to real rewards have

This research was supported by Grant DA11692-03 from the National Institute on Drug Abuse. We thank Amy Prue for her invaluable assistance in collecting and organizing the data. We are also very grateful to all of the lottery organizations that supplied us with data. We specifically thank Maxine Ballard, Tim Brown, Sylvia Buzzell, Shannon Cadres, Alan Hussey, J. B. Landroche, Sandra Neal, Stepheni Schlinker, Charles Strutt, and Peter Volpe for the time and effort they put into providing the information we requested. Address correspondence to F. Baker, who is now at the Veterans Affairs Palo Alto Health Care System, 795 Willow Road (MPD 152), Menlo Park, CA 94025 (e-mail: forest.baker@ med. va.gov).

Note-This article was accepted by the previous editorial team, while John T. Wixted was editor. never used monetary rewards greater than $\$ 250$ (for reviews, see Kirby, 1997, and Johnson \& Bickel, 2002). Therefore, studying lottery payment decisions provides a unique opportunity to test whether theories of choice, based on laboratory studies, generalize to real-world decisions that involve large amounts of money.

The following sections explore two predictions that theories of choice make concerning lottery players' payment preferences for the annuity and the cash payment options in real estate lotteries.

\section{The Effect of Diminishing Marginal Utility on Jackpot Payment Preference}

A common finding is that the relationship between value and amount is a concave utility function (Kahneman \& Tversky, 1984; Rachlin, Logue, Gibbon, \& Frankel, 1986). Figure 1 shows a hypothetical value function that reflects diminishing marginal utility. In fact, Loewenstein and Prelec (1992) theorized that after some large dollar amount, the slope of the value function would eventually approach zero. According to diminishing marginal utility, the percent increase in value, as one goes from $\$ 12$ million to $\$ 24$ million, would be less than the percent increase as one goes from $\$ 6$ million to $\$ 12$ million. Therefore, as jackpot size increases, the subjective difference in value between the cash and annuity payment options should decrease and lottery players should become more indifferent between the two payment options.

Another factor that reduces the value of the annuity option relative to that of the cash option is that payment of the annuity is delayed. The degree to which the value of a delayed reward is discounted because of delay is generally well described by Mazur's (1987) hyperbolic decay function:

$$
v=\frac{A}{1+k D},
$$




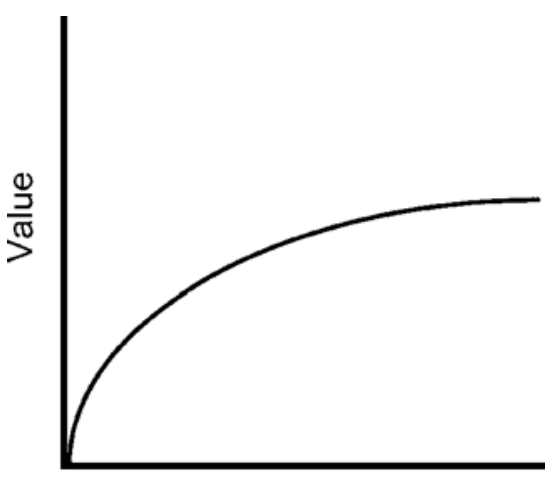

Amount

Figure 1. A hypothetical value function.

where $v$ is the present value of a reward, $A$ is the undiscounted value of the reward, $D$ is the delay to the reward, and $k$ is a free parameter that represents how quickly a reward loses value as it is delayed. When $k$ is equal to zero, delaying a reward does not affect its present value, but as the value of $k$ increases, the present value of a reward is more negatively affected by delay.

Equation 1 describes how a single reward is delay discounted, but the annuity payment option in a lottery produces a string of annual payments. Mazur (1986), using pigeons as subjects, found that the value of a series of delayed rewards is adequately described by the sum of the discounted values of each reward. Thus, even though the annuity payment option offers a larger amount of money than the cash payment option does, the subjective value of the annuity option is delay discounted, bringing its value closer to the value of the cash option.

If we assume that the delay discounting rate is unaffected by the size of a jackpot, preference for the annuity payment option should decrease as jackpot size increases, simply because of diminishing marginal utility. The delay discounting rate, however, has been shown to decrease as the magnitude of a reward increases; this is referred to as the magnitude effect (Chapman \& Winquist, 1998; Green, Myerson, \& McFadden, 1997; Kirby \& Maraković, 1996). Thus, with larger jackpots, the annuity option should retain more of its relative value since it is delay discounted at a lower rate. The magnitude effect may then retard the effects of diminishing marginal utility on the relative value of the annuity option. In other words, as a jackpot size increases, preference for the annuity payment option decreases because of diminishing marginal utility, but at the same time, preference for it increases because of a lower rate of delay discounting.

In summary, as jackpot size increases, the relative value of the annuity option is influenced by two opposing forces: diminishing marginal utility, and the magnitude effect. These two forces should influence lottery players' jackpot payment decisions when they buy a ticket and after they have won. If the effect of diminishing marginal utility outweighs the magnitude effect, then preference for the annuity payment option will decrease as jackpot size increases.

\section{The Effect of Crossing Discount Functions on Jackpot Payment Preference}

When the choice between the cash and annuity payment options was initially introduced, state lotteries required players to make their choice when they bought a ticket. This was done to protect winners from paying unnecessary federal taxes. If no paymentoption was selected on a ticket, then, by default, it was assigned the annuity payment option.

In 1999, the federal tax law was changed, giving winners up to 60 days after they won to choose a payment option. After the 60-day period, claimed jackpots were automatically paid (and taxed) as annuities. Most state lotteries have recently updated their rules and now have their players choose a payment option after they win instead of at the time of ticket purchase.

After the tax laws changed in 1999, some state lotteries, as they were updating their games, required players to choose a payment option at the time of ticket purchase, but then also gave players another opportunity to choose a payment option after they won. This created a situation where winners could abandon their original choice and exhibit a preference reversal.

Preference reversals may reflect crossing discount functions (Rachlin, Castrogiovanni, \& Cross, 1987; Rachlin \& Green, 1972). At the time of ticket purchase, the cash option is highly improbable, but it will be paid immediately (ignoring the short delay to the drawing), whereas the annuity option is both improbable and delayed. Choice studies have shown that the present value of a reward is discounted by both uncertainty and delay (Kahneman \& Tversky, 1984; Loewenstein \& Prelec, 1992; Rachlin et al., 1986). Thus, at the time of ticket purchase, the value of the cash option is probability discounted, whereas the value of the annuity option is both probability and delay discounted. After winning, however, the values of the cash and annuity options are no longer probability discounted. Instead, after winning, a player is simply faced with a choice between the immediate cash option and the delayed annuity option. If discount functions for the cash and annuity options cross at some point between the time of ticket purchase and after winning, then players should exhibit preference reversals.

Figure 2 illustrates how, on the basis of crossing discount functions, players may prefer the annuity option at ticket purchase, but then later prefer the cash option after winning. ${ }^{2}$ A player buys a ticket at Time 0 and then wins the lottery at Time 1 . The distance between Times 0 and 1 represents the expected delay before winning the lottery. The distances between Times 1 and 2 and between Times 2 and 3 represent the delay between annuity payments. For simplicity, all of the intervals in Figure 2 are equal, but the expected delay to winning a real state lottery would actually be much greater than the interval between annuity payments (i.e., much longer than 1 year).

The values in Figure 2 are based on three assumptions. The first assumption is that both uncertain and delayed rewards are discounted according to Equation $1 .^{3}$ When a reward is uncertain, $D$ in Equation 1 represents the expected delay (Rotter, 1954). For example, if a fair coin is 

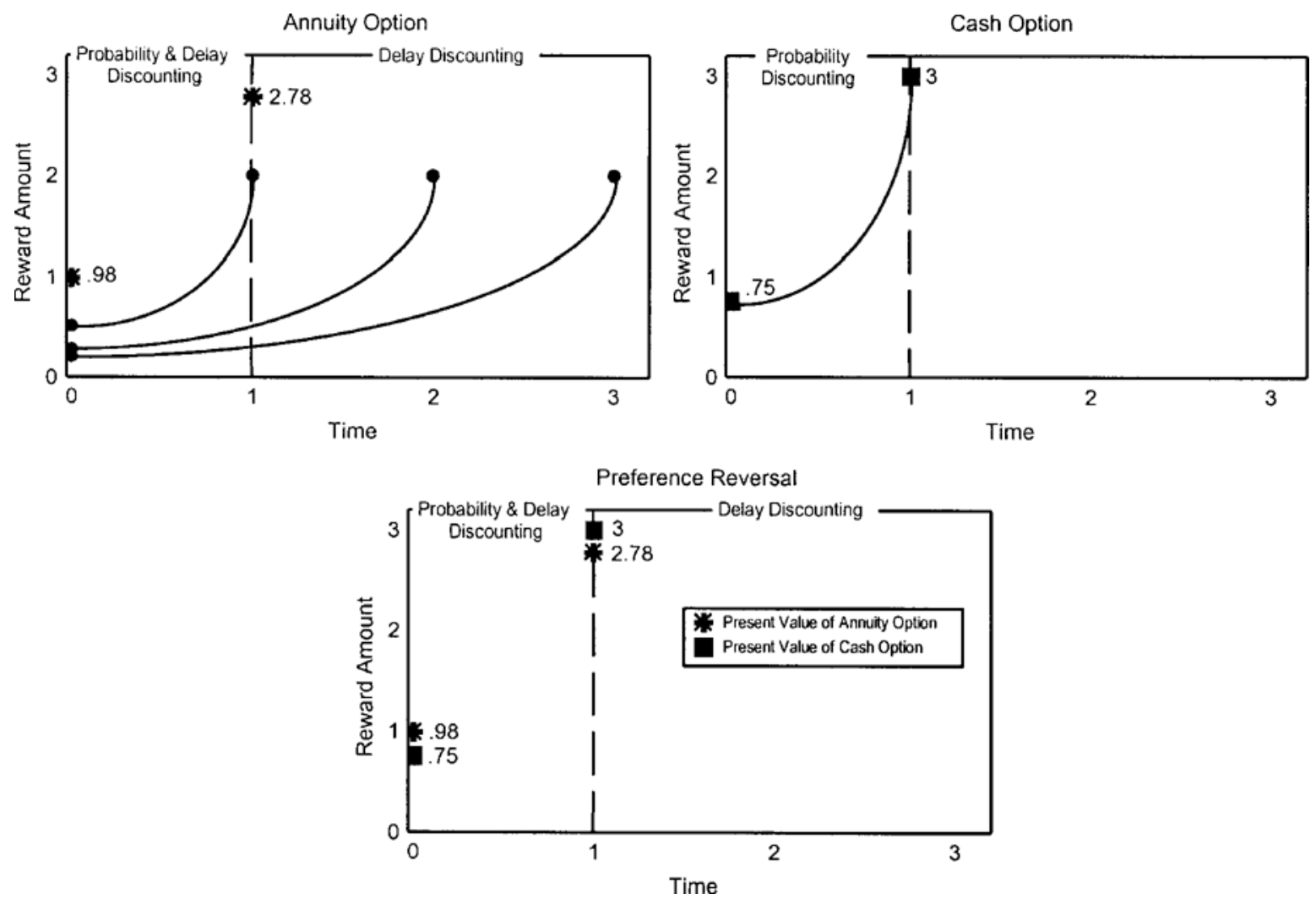

Figure 2. This figure illustrates how crossing discount functions may cause players to prefer the annuity option at ticket purchase but later prefer the cash option after winning. The annuity option (upper left graph) consists of three payments, each worth two reward units (for a total of six reward units). The first payment is at Time 1 , the second is at Time 2 , and the third is at Time 3. A player purchases a lottery ticket at Time 0 and then wins at Time 1 . The time interval between Time 0 and Time 1 represents the expected delay till winning the lottery. The cash option (upper right graph) consists of one payment of three reward units at Time 1. The lower graph compares the present values of the annuity and cash options at the time of ticket purchase (Time 0 ) and after winning (Time 1). The present value of the annuity option is greater than the present value of the cash option at the time of ticket purchase, but the opposite is true after winning (assuming that $k=3$ in Equation 1 ).

flipped once an hour, then, on the average, the expected delay for "heads" is one hour (the first flip is immediate and the second flip is an hour later). Thus, as the probability of receiving a reward decreases, the present value of the reward also decreases (Rachlin, Brown, \& Cross, 2000; Rachlin, Raineri, \& Cross, 1991). The second assumption is that the discount rate is the same for both uncertain and delayed rewards (Rachlin et al., 1986). Thus, when a reward is both uncertain and delayed, $D$ in Equation 1 is equal to the sum of the delay and the expected delay. The third assumption is that the present value of the annuity option is the sum of each of the discounted annuity payments (Mazur, 1986).

In Figure 2, the annuity option (upper left graph) consists of three payments, each of which is worth two reward units (for a total of six reward units). The first payment is at Time 1, the second is at Time 2, and the third is at Time 3. At ticket purchase (Time 0), due to probability and delay discounting, the present value of the annuity option is .98 (assuming that $k=3$ in Equation 1). After winning, due only to delay discounting, the present value of the annuity option is 2.78 . The cash option (upper right graph) consists of one payment of three reward units at Time 1. At ticket purchase, due to probability discounting, the present value of the cash option is .75. After winning, the value of the cash option is not discounted and is therefore equal to 3 . The lower graph compares the present values of the annuity and cash options at the time of ticket purchase (Time 0) and after the lottery has been won (Time 1). The present value of the annuity option is greater than the present value of the cash option at the time of ticket purchase, but the opposite is true after winning. Thus, given a sufficient rate of discounting, lottery winners may switch from the annuity to the cash option after winning, but they should never switch from the cash option to the annuity option.

The parameters in Figure 2 are contrived, but whether discount functions cross depends on both the rate of discounting and the interval between the receipt of the smaller reward and the receipt of the larger reward. If reward value is discounted by uncertainty and delay, hyperbolic discount functions will eventually cross, given that the inter- 
val between the receipt of the smaller reward and the receipt of the larger reward is long enough. The lower the rate of discounting, the greater the interval between the receipt of the smaller reward and the receipt of the larger reward that is required for the discount functions to cross. In real state lotteries, the interval between the receipt of the smaller reward (cash) and the receipt of the larger reward (annuity) is fixed, so that switching from the annuity to the cash option implies a sufficient rate of discounting.

\section{METHOD}

Archival data on ticket sales and payment decisions made by lottery winners was obtained from seven state and three multistate lotteries that at one point in time offered players a choice between the cash and annuity payment options. ${ }^{4}$ To examine preference as a function of jackpot size and preference reversals, we requested two kinds of data from the lottery organizations: (1) for each drawing, the advertised jackpot, the number of tickets sold that were assigned the annuity payment option, and the number of tickets sold that were assigned the cash payment option; (2) for each drawing in which there was at least one winner, the number of winners, the jackpot size (split equally among each winning ticket), and the payment option the that winner(s) selected at the time of ticket purchase and after winning. 5

\section{RESULTS}

\section{Evidence of Diminishing Marginal Utility}

Figure 3 shows the proportion of tickets sold in which the annuity payment option was selected, as a function of the advertised jackpot size for the Michigan, Ohio, and Washington state lotteries (the only states that reported this information). In keeping with diminishing marginal utility, the proportion of annuity tickets sold decreased as the ad- vertised jackpot size increased in all three state lotteries. These negative correlations were significant in the Michigan, Ohio, and Washington state lotteries $(r=-.20, p=$ $.03 ; r=-.60, p<.01$; and $r=-.26, p<.01$, respectively).

The filled circles in Figure 4 represent the proportion of winners who chose the annuity payment option within 60 days after they had won (left $y$-axis) across increasing jackpot size intervals. The open squares represent the total number of observations that these proportions are based on (right $y$-axis). These data include drawings from all seven state and three multistate lotteries. Again in keeping with diminishing marginal utility, the proportion of winners who chose the annuity payment option decreased as jackpot size increased. A Spearman's correlation between the proportion of winners who chose the annuity payment option and jackpot size interval was significant $\left(r_{s}=-.52\right.$, $p=.04)$.

\section{Evidence of Crossing Discount Functions}

The only state lotteries able to provide data on players' jackpot payment preferences both at ticket purchase and after winning were Georgia, Michigan, and Ohio. Table 1 shows the number of winners who chose the cash and the annuity options at ticket purchase and the number of winners who switched to the cash and annuity options after winning, for the three state lotteries. Of the 62 winners from the Georgia and Ohio state lotteries, 40 chose the cash option at ticket purchase and 22 chose the annuity option. In agreement with crossing discount functions, none of the 40 winners who initially chose the cash option switched to the annuity option, whereas 10 of the 22 winners who initially chose the annuity option switched to the cash option $(45 \%)\left[\chi^{2}(1, N=62)=21.67, p<.01, \phi=.59\right]$.

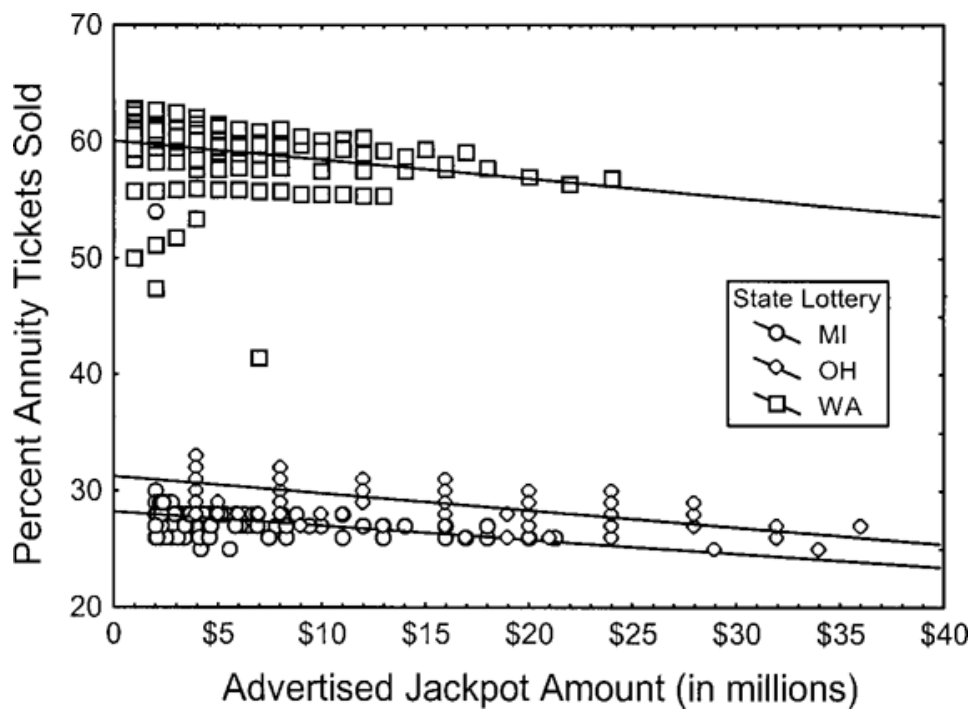

Figure 3. Proportion of tickets sold in which the annuity payment option was selected as a function of the advertised jackpot size for the Michigan, Ohio, and Washington state lotteries. Best-fit regression lines are shown for ticket sales in each lottery. Note that the $y$-axis does not start at zero. 


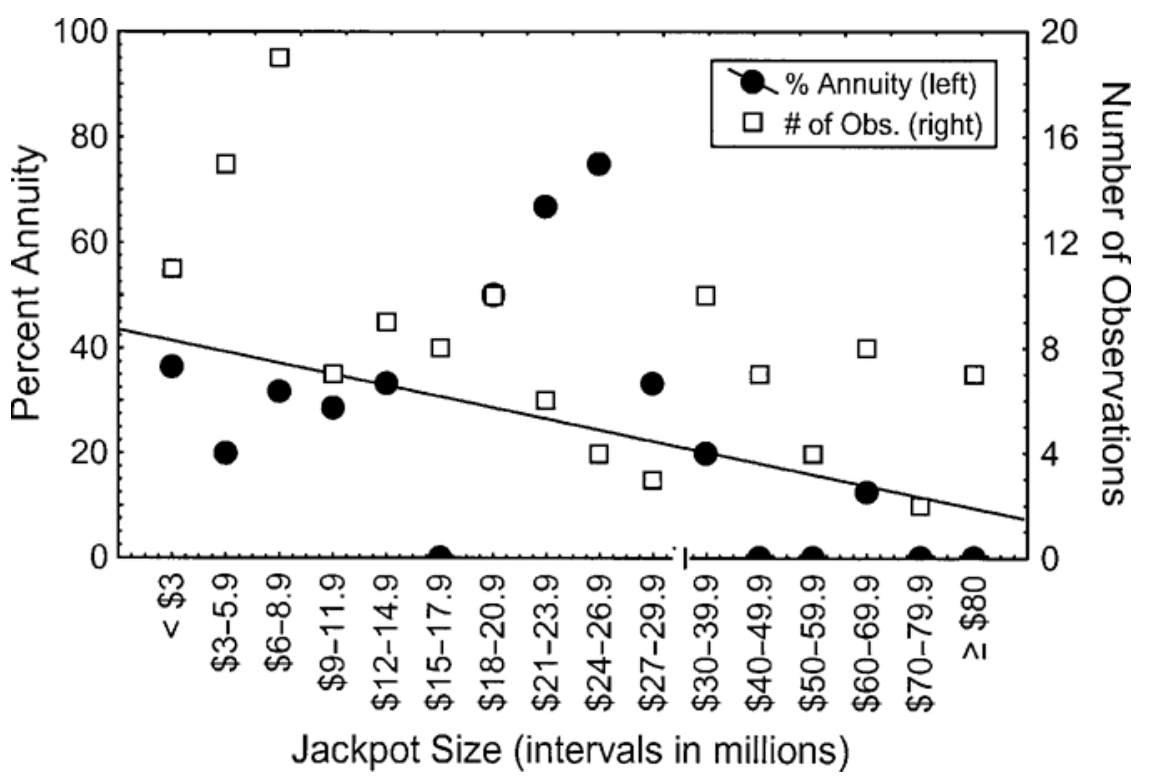

Figure 4. Proportion of winners who chose the annuity payment option (within 60 days after they had won) on the left $y$-axis and the actual number of observations on right $y$-axis across increasing jackpot size intervals. A best-fit regression line is shown for the percentage of winners who chose the annuity payment option. Note that the jackpot intervals are not equal.

\section{DISCUSSION}

The results of this naturalistic study suggest that theories of diminishing marginal utility and delay and probability discounting, which are based predominately on laboratory studies, may explain real-world decisions involving large sums of money. Theories of choice assume that rewards are probability and delay discounted, and this is supported by the fact that, on the average, lottery players preferred the cash option (a smaller immediate reward) to the annuity option (a larger delayed reward). In addition, the finding that preference for the annuity option decreased as jackpot size increased, both at the time of ticket purchase and after winning, supports the concept of diminishing marginal utility. That is, as jackpot size increases, the subjective difference in amount between the cash and annuity options decreases. Finally, the fact that many lottery players switched from the annuity to the cash option after winning, but not vice versa, is congruent with crossing discount functions.

Table 1

Number of Winners Who Chose the Cash and Annuity Payment Options

\begin{tabular}{|c|c|c|c|c|}
\hline \multirow[b]{3}{*}{ Lottery } & \multirow{2}{*}{\multicolumn{2}{|c|}{ At Ticket Purchase }} & \multicolumn{2}{|c|}{ After Winning } \\
\hline & & & \multirow{2}{*}{$\begin{array}{c}\text { Switched from } \\
\text { Annuity to Cash }\end{array}$} & \multirow{2}{*}{$\begin{array}{l}\text { Switched from } \\
\text { Cash to Annuity }\end{array}$} \\
\hline & Cash & Annuity & & \\
\hline Georgia & 19 & 4 & 1 & 0 \\
\hline Michigan & 13 & 5 & 2 & n.a.* \\
\hline Ohio & 21 & 18 & 9 & 0 \\
\hline
\end{tabular}

*Not applicable for Michigan (see note 5).
The proportion of annuity tickets sold decreased as the advertised jackpot size increased, which suggests that the effect of diminishing marginal utility on choice is not completely negated by the magnitudeeffect. That is, even though larger annuity jackpots may be delay discounted at a lower rate than that for smaller annuity jackpots, preference for the annuity option continued to decline as jackpot size increased. In fact, there is reason to believe that the decline in preference for the annuity option as jackpot size increases may be even stronger than what is reported here. Total ticket sales for lotteries reliably increase as jackpot size increases, and this is partly due to new players buying tickets (Clotfelter \& Cook, 1989). Players who are unfamiliar with buying lottery tickets may fail to make a payment choice on a ticket and thus be assigned the default option, the annuity payment. Therefore, larger jackpots may have attracted neophyte players who failed to make a payment choice on their tickets, and this may have moderated the finding that preference for the annuity payment option decreased as jackpot size increased.

One unexpected finding was that the Washington state lottery consistently sold a higher percentage of annuity tickets than did the Michigan and Ohio lotteries. One plausible explanation for this difference is that a higher percentage of Washington lottery players were unaware that they could choose between the two payment options. This may have been due to some shortcomings in the Washington lotteries' attempt to publicize the rules and choices involved in the game. However, regardless of this main effect, annuity ticket sales still decreased as jackpot size increased.

Although the results of this study bode well for current theories of choice, lottery players' decisions may also be 
influenced by other factors such as the current state of the economy or advice from financial consultants. If the stock market is doing well, lottery players may choose the cash payment option, believing that they will have enough selfcontrol to invest their winnings. All of the lotteries included in this study encourage their winners to consult a financial expert before they choose a payment option, but none of them collected data on the number of winners who actually heeded this advice. Financial consultants are, undoubtedly, also sensitive to delay and thus would probably prefer to receive their investment fees sooner rather than later. Therefore, lottery winners who consult financial experts may be advised to choose the cash option.

Although financial consultation may provide an alternative explanation for the observed preference reversals, it does not rule out an explanation based on crossing discount functions. The financial consultation explanation suggests that players do not consider the payment options until after they have won and have consulted with a financial advisor. However, the extant data suggest that players do consider the payment options at ticket purchase, since the percentage of annuity tickets sold was inversely related to the advertised jackpot size. Furthermore, although naturalistic studies can provide external validity for theories based on laboratory studies, they, by their very nature, are ill equipped to confidently rule out alternative explanations. Therefore, although other factors may account for the preference reversal data, the possibility of crossing utility functions remains a viable explanation.

The results of the present study suggest that diminishing marginal utility and delay and probability discounting affect decisions that involve very large amounts of real money. Few individuals will ever be faced with choices that involve such large magnitudes of money, but choices of this magnitude are typical for many institutions and government agencies making budgetary decisions (Logue \& Anderson, 2001). In these situations, diminishing marginal utility and discounting may make it difficult for policymakers to fully appreciate projects that raise larger amounts of revenue over longer periods of time as opposed to projects that raise smaller amounts of revenue more quickly or with more certainty. Furthermore, long-term projects that yield larger returns may often be abandoned when smaller short-term alternatives suddenly become available.

\section{REFERENCES}

Chapman, G. B., \& Winquist, J. R. (1998). The magnitude effect: Temporal discount rates and restaurant tips. Psychonomic Bulletin \& Review, 5, 119-123.

Clotfelter, C. T., \& Cook, P. J. (1989). Selling hope: State lotteries in America. Cambridge, MA: Harvard University Press.

Green, L., Myerson, J., \& MCFAdDEn, E. (1997). Rate of temporal discounting decreases with amount of reward. Memory \& Cognition, 25, 715-723.

JoHnson, M. W., \& BiCKel, W. K. (2002). Within-subject comparison of real and hypothetical money rewards in delay discounting. Journal of the Experimental Analysis of Behavior, 77, 129-146.
Kahneman, D., \& TVersky, A. (1984). Choices, values, and frames. American Psychologist, 39, 341-350.

KIRBY, K. N. (1997). Bidding on the future: Evidence against normative discounting of delayed rewards. Journal of Experimental Psychology: General, 126, 54-70.

Kirby, K. N., \& Marakovic, N. N. (1996). Delay-discounting probabilistic rewards: Rates decrease as amounts increase. Psychonomic Bulletin \& Review, 3, 100-104.

Loewenstein, G., \& Prelec, D. (1992). Anomalies in intertemporal choice: Evidence and interpretation. Quarterly Journal of Economics, 107, 573-597.

Logue, A. W., \& Anderson, Y. D. (2001). Higher-education administrators: When the future does not make a difference. Psychological Science, 12, 276-281.

MAZUR, J. E. (1986). Choice between single and multiple delayed reinforcers. Journal of the Experimental Analysis of Behavior, 46, 67-77.

MAZUR, J. E. (1987). An adjusting procedure for studying delayed reinforcement. In M. L. Commons, J. E. Mazur, J. A. Nevin, \& H. Rachlin (Eds.), Quantitative analysis of behavior: Vol. V. The effect of delay and of intervening events on reinforcement value (pp. 55-73). Hillsdale, NJ: Erlbaum.

RACHLIN, H., BROWN, J., \& CROSS, D. (2000). Discounting in judgments of delay and probability. Journal of Behavioral Decision Making, 13, 145-159.

Rachlin, H., Castrogiovanni, A., \& Cross, D. (1987). Probability and delay in commitment. Journal of the Experimental Analysis of Behavior, 48, 347-353.

RACHLin, H., \& GREen, L. (1972). Commitment, choice and selfcontrol. Journal of the Experimental Analysis of Behavior, 17, 15-22.

Rachlin, H., Logue, A. W., Gibbon, J., \& Frankel, M. (1986). Cognition and behavior in studies of choice. Psychological Review, 93, 33-45.

RACHLIN, H., RAINERI, A., \& CROSs, D. (1991). Subjective probability and delay. Journal of the Experimental Analysis of Behavior, 55, 233-244. ROTTER, J. B. (1954). Social learning \& clinical psychology. Englewood Cliffs, NJ: Prentice-Hall.

\section{NOTES}

1. The annual payments actually increase slightly from year to year, with the first payment being the smallest and the last payment being the largest. These payments are of course subject to federal, state, and local taxes.

2 . We thank an anonymous reviewer for suggesting this figure.

3. Rachlin et al. (1986) actually used an $h$ parameter instead of a $k$ parameter in Equation 1 when dealing with probability discounting.

4. The seven state and three multistate lotteries (and when their drawings occurred) were Colorado (July 1994 to November 2000), Georgia (September 1998 to November 2000), Michigan (July 1999 to August 2000), New York (February 1996 to October 2000), Ohio (June 1999 to October 2000), Texas (February 1997 to October 2000), Washington (May 1998 to October 1999), PowerBall (December 1997 to September 2000), The Big Game (January 1999 to October 2000), and Tri-State MegaBucks (August 1997 to June 2000). The PowerBall lottery is offered in Arizona, Connecticut, Delaware, District of Columbia, Idaho, Indiana, Iowa, Kansas, Kentucky, Louisiana, Minnesota, Missouri, Montana, Nebraska, New Hampshire, New Mexico, Oregon, Rhode Island, South Dakota, West Virginia, and Wisconsin. The Big Game lottery is offered in Georgia, Illinois, Maryland, Massachusetts, Michigan, New Jersey, and Virginia. The Tri-State MegaBucks lottery is offered in Maine, New Hampshire, and Vermont.

5. The Michigan lottery allowed only those winners who chose the annuity payment option on their ticket to switch to the cash option, whereas the Georgia and Ohio lotteries gave all winners another chance to choose between the two options, regardless of the option that they picked when they bought a ticket.

(Manuscript received March 13, 2001; revision accepted for publication April 12, 2002.) 